\title{
Video-assisted thoracoscopic surgery versus muscle-sparing thoracotomy for non-small cell lung cancer: a systematic review and meta-analysis
}

Zihuai Wang ${ }^{1,2+}$, Long Pang ${ }^{2 \dagger}$, Jiexi Tang ${ }^{2}$, Jiahan Cheng ${ }^{1,2}$, Nan Chen ${ }^{1,2}$, Jian Zhou ${ }^{1,2}$ and Lunxu Liu ${ }^{1,2^{*}}$

\begin{abstract}
Background: It has been widely accepted that video-assisted thoracoscopic surgery (VATS) lobectomy is superior to conventional open thoracotomy lobectomy in many aspects. However, the direct comparison between VATS and Muscle-sparing thoracotomy (MST) has not been widely conducted. We aimed to compare the perioperative outcomes in non-small cell lung cancer (NSCLC) patients following VATS and MST.

Methods: PubMed, EMBASE, the Cochrane Library and Web of Science were searched for relevant studies. The retrieval time was up to April 24, 2019. Studies investigating the comparison of video-assisted thoracoscopy and muscle-sparing thoracotomy were included in our meta-analysis. Odds ratio and mean differences with 95\% confidential interval were applied to determine the effectiveness of dichotomous or continuous variables respectively.

Results: A total of 10 studies were included with 1514 patients. Compared with MST, the incidence of postoperative complications in VATS $[\mathrm{OR}=0.54 ; 95 \% \mathrm{CI}(0.4,0.73) ; P<0.001]$ and the hospital stay $[\mathrm{MD}=-1.5$; $95 \% \mathrm{Cl}(-2.28,-0.73) ; P=0.0001]$ decreased significantly, chest tube drainage time $[\mathrm{MD}=-0.71 ; 95 \% \mathrm{Cl}(-1.18,-0.24)$; $P=0.003]$ were shorter and the intraoperative blood loss $[\mathrm{MD}=-43.87 ; 95 \% \mathrm{CI}(-73.66,-14.08) ; P=0.004]$ were less in VATS group. VATS also showed a relatively longer operative time $[\mathrm{MD}=17.11 ; 95 \% \mathrm{Cl}(2.38,31.85) ; P=0.02]$. However, no significant differences were observed in numbers of resected lymph nodes, postoperative mortality, postoperative pneumonia and postoperative bleeding.

Conclusion: Compared with MST, VATS was associated with lower incidence of postoperative complications, shorter length of hospital stay, less intraoperative blood loss and less chest tube drainage, which showed that VATS was a comparable method to MST. Meanwhile, these results should be further conformed by more randomized control trials.
\end{abstract}

Keywords: Non-small cell lung cancer, Video-assisted thoracoscopic surgery, Muscle-sparing thoracotomy

\footnotetext{
* Correspondence: lunxu_liu@aliyun.com

†Zihuai Wang and Long Pang contributed equally to this work.

${ }^{1}$ Department of Thoracic Surgery, West China Hospital, Sichuan University,

No. 37, Guoxue Alley, Chengdu 610041, Sichuan, China

${ }^{2}$ West China School of Medicine, Sichuan University, No. 37, Guoxue Alley,

Chengdu 610041, Sichuan, China
}

(c) The Author(s). 2019 Open Access This article is distributed under the terms of the Creative Commons Attribution 4.0 International License (http://creativecommons.org/licenses/by/4.0/), which permits unrestricted use, distribution, and reproduction in any medium, provided you give appropriate credit to the original author(s) and the source, provide a link to the Creative Commons license, and indicate if changes were made. The Creative Commons Public Domain Dedication waiver (http://creativecommons.org/publicdomain/zero/1.0/) applies to the data made available in this article, unless otherwise stated. 


\section{Background}

Lung cancer is the most commonly diagnosed cancer around the world and the leading cause of cancer death, with the highest mortality rate among men and the second mortality rate among women [1,2]. Every year, 1.6 million new cases are diagnosed globally [3]. Additionally, prognosis of lung cancer is poor-the 5-year survival rate for lung cancer is only $18 \%$ according to NCCN guideline $[4,5]$.

Surgery still remains the most commonly used therapy for early stage lung cancer patients [6]. Posterolateral thoracotomy (conventional thoracotomy) and muscle sparing thoracotomy(MST) [7-9] were thought to be the main method for a long time. Comparing with conventional thoracotomy, MST had better postoperative outcomes [10]. However, with the rapid development of technology, video-assisted thoracoscopic surgery (VATS) has been widely validated in recent years $[11,12]$. Minimal invasive surgery has potential superiorities of optimizing surgical indications, including safety, feasibility, less invasiveness, and a better quality of life [13]. Yet, a direct comparison between the effects of MST and VATS is still vacant.

Via a meta-analytic approach, the aim of this study is to compare these two methods in terms of perioperative outcomes.

\section{Methods}

\section{Search strategy}

No previous protocol has been conducted for this review. PubMed, EMBASE, the Cochrane Library and Web of Science were independently searched by two reviewers (Long Pang and Zihuai Wang) to identify potentially eligible literature up to April 23, 2019 with the following search items: ((()(vats) OR video assisted thoracic surgery) OR video assisted thoracoscopic) OR minimal invasive thoracic $))$ AND ((((muscle sparing thoracotomy) OR muscle sparing thoracic surgery) OR muscle sparing thoracoscopic) OR muscle sparing). Only English studies were included in our analysis. A third reviewer drew the conclusion when any disagreement appeared. All potential eligible studies were manually searched to find possible relevant publications.

\section{Study selection}

The following criteria has been set before article collection for inclusion: 1) patients with NSCLC proven pathologically; 2) compared the effects between VATS and MST; 3) RCT or cohort studies with acceptable methodological quality. The studies were excluded meeting any of the following criteria: 1) conference abstracts, reviews, letters, book chapters, animal experiments or case reports; 2) baseline characters were incomplete; 3) insufficient data for meta-analysis.

\section{Data collection}

Data collection was independently conducted by 2 reviewers. The extracted and summarized data include: first author, publication year, study design, gender of included patients, sample size and patient staging. In addition, we analyzed the outcomes of intraoperative data, postoperative complications, length of hospital stay and chest tube drainage.

\section{Quality assessment}

The quality of included RCT was assessed by Jadad scale [14], which contains randomization (0-2 points), blindness of the studies (0-2 points), and withdrawals (0-1 points). Studies with a score higher than three points were defined as high quality. The included non-randomized articles were assessed by Newcastle-Ottawa Scale [15]. NOS comprises three perspectives with a maximum of 9 stars when assessing non-randomized control trials. Studies with scored 0 to 3,4 to 6 and 7 to 9 were taken as low medium and high quality, respectively.

\section{Statistical analysis}

Review Manager V5.3 (The Cochrane Collaboration, Software Update, Oxford, UK) was used to extract, pool and analyze data. Dichotomous outcomes were evaluated by odds ratio (OR) and a corresponding 95\% confidence intervals $(\mathrm{CI})$. The curative effect in continuous variables was expressed as mean difference (MD) with corresponding 95\% confidence intervals $(\mathrm{CI})$. The results were identified as statistically significant when the $P$ value less than 0.05 . Statistical heterogeneity was assessed by the $\mathrm{I}^{2}$ statistics. If $\mathrm{I}^{2}<50 \%$, it represents no statistically significant heterogeneity exists across studies and the fixedeffects model would be used otherwise the randomizedeffects model would be applied. Sensitivity analysis was performed by sequential removal of each study. Funnel plots generated by Review Manager V5.3 were used to estimate the potential publication bias in included articles. All $P$ values were two-sided. A significant difference was defined as $P<0.05$.

\section{Results}

\section{Selection process}

In total, 235 papers were screened by the initial database search. After reviewing the abstract, 218 articles were excluded. Another 17 papers were reviewed in full text. Finally, a total of 10 eligible studies [16-25] with 1514 patients were included in this meta-analysis after fully evaluation. Although slight differences exist in VATS and MST among institutions. VATS surgery was all presented with a video camera inserted into the pleural space without rib spreading. And Muscle-sparing thoracotomy was all described as preserving related muscles. Latissimus dorsi and serratus anterior were retracted or 


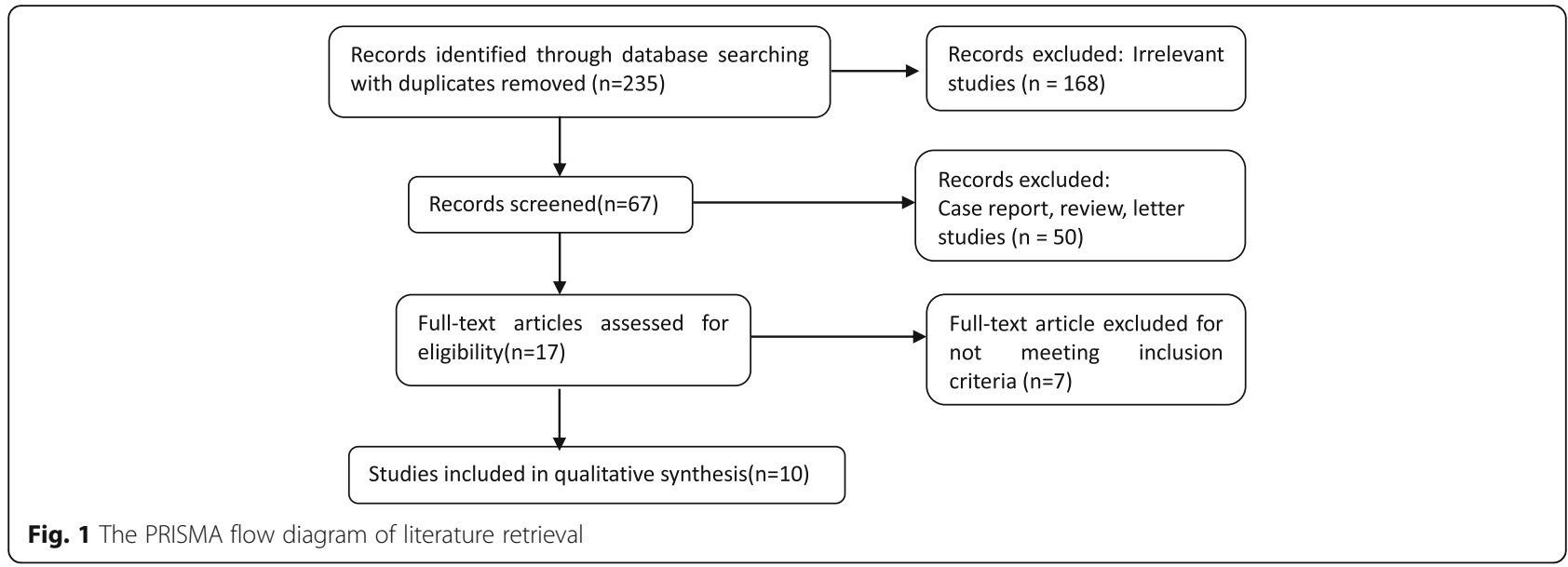

split in the direction of the fibers. After detailed screening, the entire perioperative management of each article is ensured to be comparable. Figure 1 shows the process of article selection.

\section{Study characteristics and risk of bias assessment}

All included articles were published before April 1st, 2019. Among the 1514 patients, 711(46.7\%) of them underwent VATS, 803(53.3\%) of them underwent MST. There were 1 RCT, 3 prospective studies and 5 retrospective studies. Mostly, the studies were composed of early stage patients. Three articles underwent propensity score matching $[17,19,22]$. Table 1 shows the detailed characteristics of included studies. The quality of included studies was assessed by Jadad score for the RCT and NOS for the cohort studies. In Kirby's work, the method of randomization was not mentioned nor did the withdrawal or blindness of the patients [18]. Therefore, it was evaluated as low quality with only one score. Table 2 showed the quality assessment result of all cohort studies [16, 17, 19-24].

\section{Primary outcome measures}

Eight studies [17-22, 24, 25] focused on postoperative complications assessing the safety of surgeries. A total of 86 patients in VATS group and 153 patients in MST group had postoperative complications. The pooled analysis showed that a significant reduction in the incidence of total postoperative complications [OR: $0.54,95 \% \mathrm{CI}$ (0.40, 0.73), $P<0.0001$ ] was found in VATS group (Fig. 2a). The result was stable with no heterogeneity $\left(\mathrm{I}^{2}=0, P=0.52\right)$ or publication bias found among them. The funnel plot was shown in Fig. 3.

A reduction of intraoperative blood loss in VATS group was reported in 4 studies including 536 patients. There was a significant decrease [MD: $-43.87,95 \% \mathrm{CI}$ ($73.66,-14.08), P=0.004]$ in VATS group comparing with MST group (Fig. 2b).

A meta-analysis of 9 studies [16-22, 24, 25] with 1421 patients showed an obvious shortened length of hospital stay [MD: $-1.50,95 \% \mathrm{CI}(-2.28,-0.73), P=0.0001]$ following the VATS. Similarly, the shorten duration of chest tube drainage [MD: $-0.71,95 \% \mathrm{CI}(-1.18,-0.24)$,

Table 1 Characteristics of the included clinical trials

\begin{tabular}{|c|c|c|c|c|c|c|c|c|}
\hline Study & Year & Country & Study design & Gender (M/F) & $\begin{array}{l}\text { Sample size } \\
\text { VATS/MST }\end{array}$ & Staging & $\begin{array}{l}\text { Propensity score } \\
\text { matching }\end{array}$ & Quality assessment \\
\hline Giudicelli & 1994 & France & Prospective & $50 / 17$ & $44 / 23$ & Pathologic Stage I to stage IV & Unmatched & NOS: 6 \\
\hline Kirby & 1995 & USA & $\mathrm{RCT}$ & $26 / 35$ & $30 / 31$ & Clinical stage I & Unmatched & Jadad: 1 \\
\hline Nomori & 2001 & Japan & Prospective & $44 / 22$ & $33 / 33$ & Clinical stage I & Unmatched & NOS: 8 \\
\hline Wang & 2010 & China & Retrospective & $175 / 141$ & $121 / 195$ & Pathologic Stage I to stage IV & Unmatched & NOS: 6 \\
\hline Ilonen & 2013 & Finland & Retrospective & $125 / 107$ & 116/116 & Clinical stage I & Matched & NOS: 7 \\
\hline Erus & 2014 & Turkey & Prospective & $35 / 20$ & $25 / 30$ & Clinical stage I & Unmatched & NOS: 8 \\
\hline Kuritzky & 2015 & USA & Retrospective & $45 / 75$ & $60 / 60$ & Clinical stage I & Matched & NOS: 8 \\
\hline Usuda & 2017 & Japan & Retrospective & $46 / 41$ & $25 / 62$ & Clinical Stage I to stage III & Unmatched & NOS: 6 \\
\hline Zhao & 2017 & China & Retrospective & $250 / 232$ & $241 / 241$ & Clinical stage I & Matched & NOS: 8 \\
\hline Menna & 2018 & Italy & Retrospective & $18 / 10$ & $16 / 12$ & Clinical Stage I & Unmatched & NOS: 7 \\
\hline
\end{tabular}

Abbreviations: non-RCT non-randomized controlled trial, $R C T$ randomized controlled trial, VATS video-assisted thoracoscopic surgery, MST muscle-sparing thoracotomy, NOS Newcastle-Ottawa Scale 
Table 2 Risk of bias assessment of included cohort studies

\begin{tabular}{|c|c|c|c|c|c|c|c|c|c|}
\hline & \multicolumn{4}{|l|}{ Selection } & \multirow[t]{2}{*}{ Comparability } & \multicolumn{3}{|l|}{ Outcome } & \multirow{2}{*}{$\begin{array}{l}\text { Tota } \\
\text { scor }\end{array}$} \\
\hline & $\begin{array}{l}\text { Exposed } \\
\text { cohort }\end{array}$ & $\begin{array}{l}\text { Non-exposed } \\
\text { cohort }\end{array}$ & $\begin{array}{l}\text { Ascertainment } \\
\text { of exposure }\end{array}$ & $\begin{array}{l}\text { Outcome } \\
\text { of interest }\end{array}$ & & $\begin{array}{l}\text { Assessment } \\
\text { of outcome }\end{array}$ & $\begin{array}{l}\text { Length of } \\
\text { follow-up }\end{array}$ & $\begin{array}{l}\text { Adequacy } \\
\text { of follow up }\end{array}$ & \\
\hline Asamura & $\bar{i}$ & $\hat{i}$ & $\hat{2}$ & is & 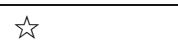 & 弥 & 弥 & $\bar{s}$ & 8 \\
\hline Chen & $i$ & 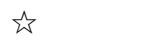 & is & $i$ & $i$ & $i$ & - & - & 6 \\
\hline Guerrera & 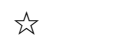 & 次 & $i s$ & 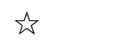 & is & $\dot{s}$ & $i s$ & $\dot{s}$ & 8 \\
\hline $\mathrm{Hu}$ & $i$ & 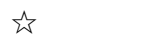 & $i s$ & $i$ & is & $i$ & $i s$ & - & 7 \\
\hline Ichinose & $\hat{s}$ & 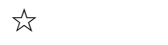 & $i s$ & $\hat{s}$ & - & 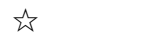 & 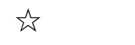 & 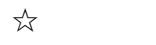 & 7 \\
\hline \|lic & $i$ & $i$ & $i s$ & $i$ & $i$ & $i$ & - & - & 6 \\
\hline Legras & $i$ & $i$ & 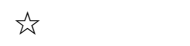 & 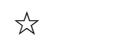 & - & $\dot{s}$ & $i s$ & $\hat{s}$ & 7 \\
\hline Li (case control) & $i$ & $i$ & $i s$ & $i$ & $i$ & $i$ & - & - & 8 \\
\hline Li (combined) & $i$ & 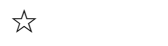 & 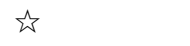 & $i$ & $i$ & $i$ & $\hat{r}$ & $\dot{\omega}$ & 8 \\
\hline Liu & $\hbar$ & 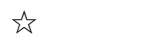 & 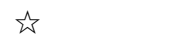 & $i$ & is & $i$ & - & - & 6 \\
\hline Luo & $i$ & 岤 & 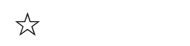 & $i$ & $i$ & $i$ & $\dot{x}$ & - & 7 \\
\hline Misthos & 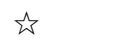 & $i$ & $i$ & $\hat{s}$ & is & $\dot{s}$ & - & - & 6 \\
\hline Misthos & $i$ & 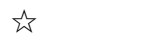 & 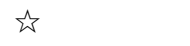 & $i$ & $i$ & $\dot{\omega}$ & - & - & 6 \\
\hline Nakagiri & $\hat{s}$ & $\hat{s}$ & $i s$ & $\hat{s}$ & $i$ & $\hat{s}$ & $\hat{s}$ & $\hat{s}$ & 8 \\
\hline Ohta & 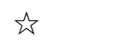 & 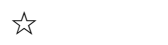 & 次 & $\dot{s}$ & $\hat{s}$ & 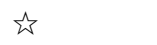 & $i s$ & $\hat{\Sigma}$ & 8 \\
\hline Prenzel & $i$ & 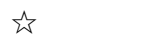 & $i s$ & $i$ & $i$ & $\dot{z}$ & - & - & 6 \\
\hline Riquet & $i$ & 放 & $i s$ & $i$ & $i$ & 访 & $i$ & 访 & 8 \\
\hline Sonobe & 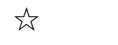 & $i s$ & - & $i$ & $i$ & 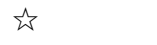 & $i$ & $i s$ & 7 \\
\hline Tanaka & $i$ & 论 & $i$ & $i$ & $i$ & $i$ & $i$ & $\sum$ & 8 \\
\hline Tomina & $i$ & 次 & $i s$ & 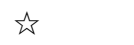 & $i$ & $\sum$ & - & - & 6 \\
\hline Tomizawa & $i$ & $i$ & $\hbar$ & $i$ & $i$ & 项 & $i$ & 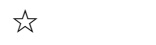 & 8 \\
\hline Wang & 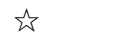 & 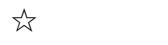 & $i$ & $\hat{s}$ & is & $i$ & is & - & 7 \\
\hline Wang & $i$ & $\sum$ & $i$ & $i$ & $i$ & $\sum$ & - & - & 6 \\
\hline Wang & $\dot{2}$ & 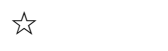 & 访 & - & is & $\dot{2}$ & - & - & 5 \\
\hline Yoshino & $i$ & $\dot{s}$ & 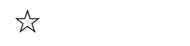 & $i$ & $i$ & $\dot{\omega}$ & - & - & 6 \\
\hline Zhang & 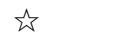 & 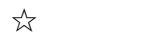 & $i$ & $i$ & 访 & $i$ & - & - & 6 \\
\hline Zhao & $i$ & $\sum$ & $i s$ & 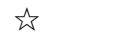 & 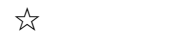 & $i$ & $i$ & - & 7 \\
\hline Zheng & 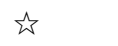 & 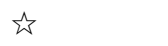 & is & $\hat{s}$ & - & $\dot{s}$ & is & - & 6 \\
\hline
\end{tabular}

Risk of bias was evaluated with use of the Newcastle-Ottawa Scale in cohort studies. A score of 7 or higher indicates a low risk of bias

$P=0.003$ ] in VATS group was found in 6 studies [16]' $[18-20,22,24]$ with 845 patients enrolled. Figure 2c described detailed outcomes as well.

\section{Secondary outcome measures}

When regarding operative time, a total of 1276 patients in 9 studies were observed, including 1 RCT and 8 cohort studies. A significant difference was discovered between 2 groups [MD: 17.11, 95\%CI $(2.38,31.85), P=$ 0.02] (Table 3). The result was stable and a high heterogeneity was observed $\left(\mathrm{I}^{2}=92 \%\right)$. However, in the included RCT, no significant difference was shown in operative time between two groups.

As for the number of resected lymph nodes, no remarkable difference was found between two groups in the 3 studies with 864 patients involved. The result showed that a comparable lymph node retrieval rate between the two groups [MD:1.25, 95\% CI $(-4.57,7.07)$, $P=0.67]$. The detailed results of number of resected lymph nodes were presented in Table 3.

Five articles discussed the postoperative mortality between two groups. However, there was no remarkable differences found in respect of postoperative mortality [OR: $1.03,95 \% \mathrm{CI}(0.38,2.80), P=0.95]$. Detailed information can be found in Table 3 .

\section{Sensitivity and publication bias}

Sensitivity analysis was applied by sequentially removing all included articles to find the source of heterogeneity and the results were stable among all included articles. 


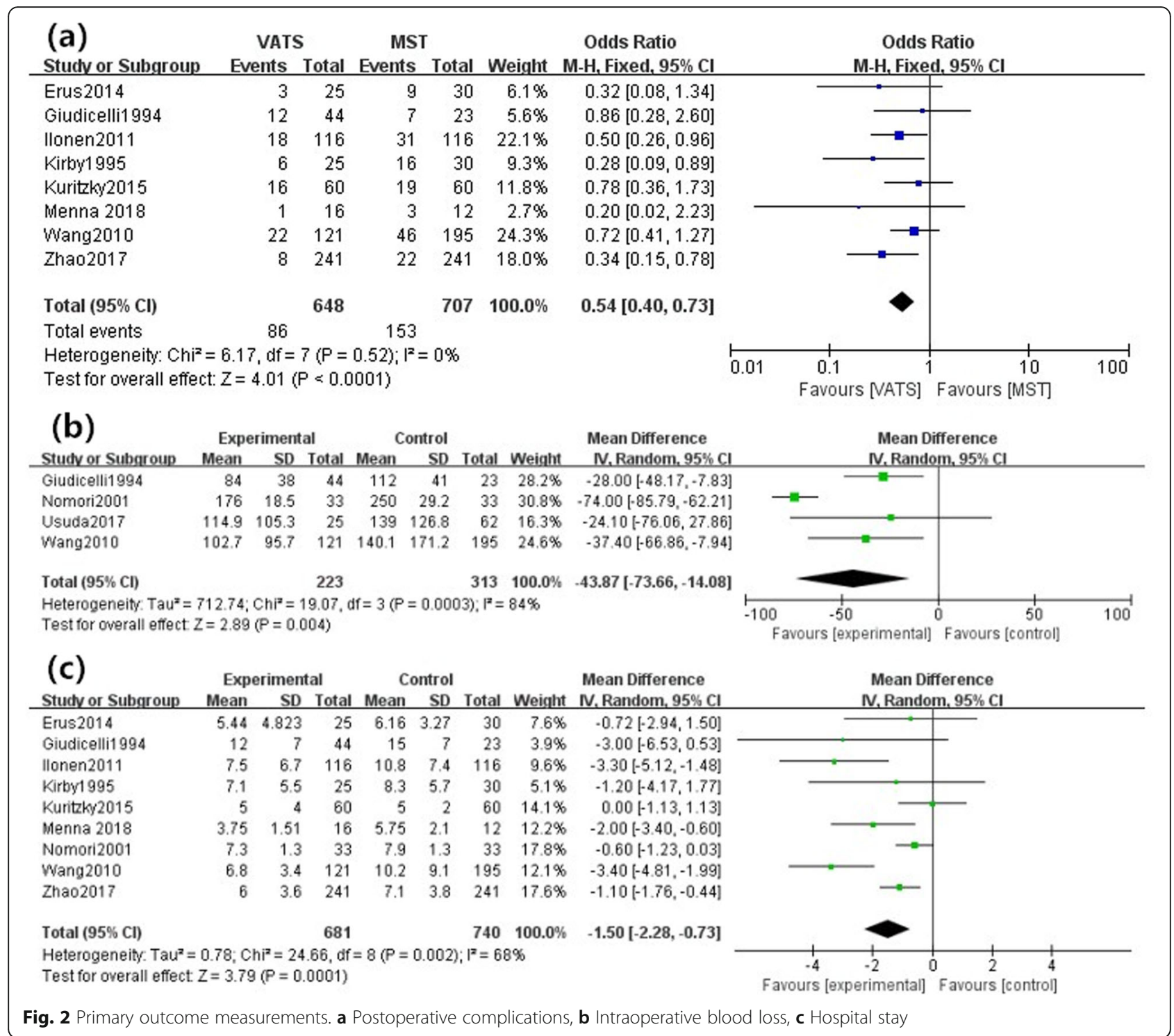

Publication bias was assessed by Review Manager V5.3 and a funnel plot for the analysis of complication rate was shown in Fig. 3.

\section{Discussion}

Minimal invasive surgery has been widely accepted in lung cancer patients especially in early stage cases. VATS has been shown to be a favorable option with less operative bleeding, shorter hospital stay and less postoperative complications [26, 27]. Accumulating amount of trials focused on the comparison between VATS and conventional thoracotomy have been published. However, few studies focused on the direct comparison between less invasive muscle-sparing thoracotomy and VATS. Only one RCT have been conducted in this field and high-quality research was limited. Our work gave a better understanding and a protocol for clinical decision and future research.

This is the first systematic review and meta-analysis designed to assess the effectiveness of VATS and MST on operable lung cancer patients. The present study indicated that VATS might be superior to the MST for less operative trauma and earlier recovery reflected by the reduced amount of intraoperative blood loss, lower rate of postoperative complications, shortened length of hospital stay and chest tube drainage. In respect of postoperative mortality, little difference was observed between VATS and MST, but this part of conclusion should be interpreted with caution for limited quantity and quality of enrolled trials.

The favorable effects following VATS support the theory that minimally invasive surgery might play an essential role of smaller intraoperative injuries and fast 


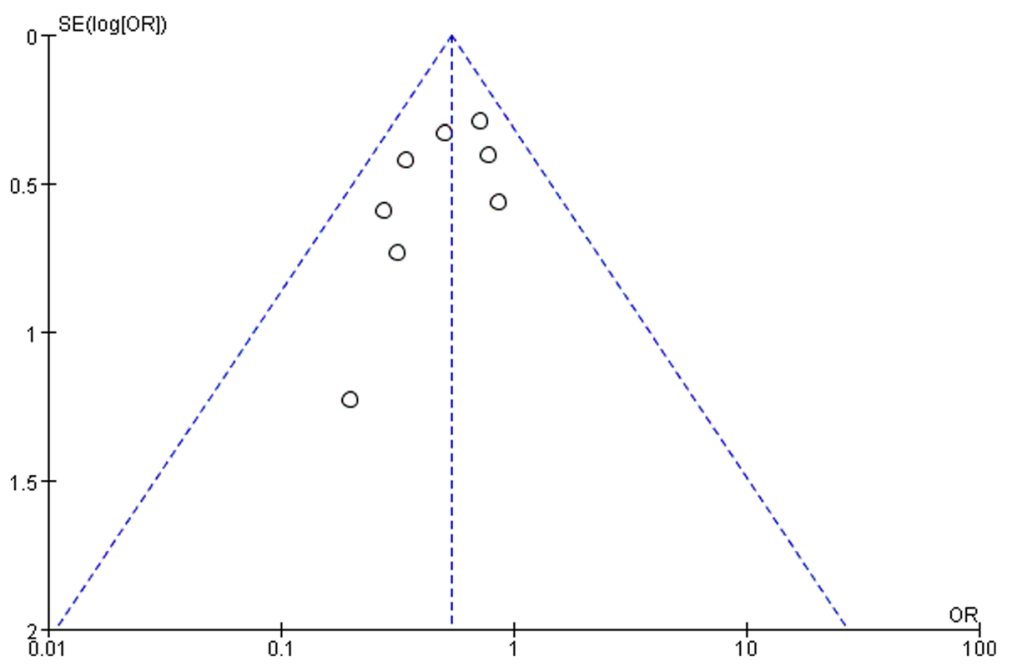

Fig. 3 Funnel plot of complication

postoperative recovery. Because of its minimal invasiveness and less chest wall trauma, VATS approach is of particular advantage to patients especially the elder ones [28]. What's more, VATS also leads to lower VAS scoring [29], which is essential for postoperative recovery. Conventional surgical approach is usually associated with a decline in pulmonary function. While after VATS approach, chemotherapy is generally better tolerated than after conventional thoracotomy, as is shown by multiple trials [30, 31]. Another important merit of VATS is that it is even more beneficial those with limited pulmonary function, which make itself more adaptive to the treatment of lung cancer with chronic obstructive pulmonary disease patients [32, 33]. A recent study discussed the inflammation differences between the two group (VATS and MST) and a reduced inflammation was found during minimal invasive surgery both locally and systematically [34]. In contrast to common view, VATS represents higher cost, many studies have reported a reduction of medical cost with VATS approach $[35,36]$, probably because of shortening the length of hospital stay and reducing healthcare resources utilization. According to a recent report published by a panel of 55 experts in VATS lobectomy, VATS approach should be the standard of care for the resection of early-stage lung cancer except in certain clinical situations [37].

There are still few limitations in our study. It was difficult to stratify potential cofounders such as age, stage of cancer, which are closely associated with pulmonary function. Furthermore, the methodological quality of some included studies was not sufficient, which might disturb analysis outcomes. Finally, the experience of surgeon and institution

Table 3 Secondary outcome measurements

\begin{tabular}{|c|c|c|c|c|c|c|c|}
\hline Outcomes & No. of studies & Pooling model & Effect size & $95 \% \mathrm{Cl}$ & & $\mathrm{P}$ & $1^{2}$ \\
\hline Operative time & 9 & Random & 17.11 & 2.38 & 31.85 & 0.02 & $92 \%$ \\
\hline No. of resected lymph nodes & 3 & Random & 1.25 & -4.57 & 7.07 & 0.67 & $95 \%$ \\
\hline Mortality & 5 & Fixed & 1.03 & 0.38 & 2.8 & 0.95 & 0 \\
\hline Pneumonia & 4 & Fixed & 1.11 & 0.48 & 2.55 & 0.8 & 0 \\
\hline Prolonged air leak & 5 & Random & 0.79 & 0.32 & 1.93 & 0.6 & $55 \%$ \\
\hline Arrythmia & 5 & Fixed & 0.48 & 0.21 & 1.06 & 0.07 & 0 \\
\hline Postoperative bleeding & 4 & Fixed & 0.62 & 0.24 & 1.61 & 0.32 & $15 \%$ \\
\hline Chylothorax & 4 & Fixed & 0.52 & 0.20 & 1.33 & 0.17 & $15 \%$ \\
\hline Duration of chest tube drainage & 6 & Random & -0.71 & -1.18 & -0.24 & 0.003 & $57 \%$ \\
\hline Postoperative pain in day 1 & 2 & Fixed & -1.02 & -1.37 & -0.66 & 0.00001 & 0 \\
\hline Postoperative pain in day 2 & 2 & Fixed & -1.42 & -1.75 & -1.09 & 0.00001 & 0 \\
\hline
\end{tabular}

*visual analogue scale was validated in pain assessment 
were inconsistent among included studies, which may contribute to the high heterogeneity.

\section{Conclusion}

In conclusion, this present systematic review and metaanalysis indicates that the benefit of VATS was superior to that of MST in the reduction of intraoperative trauma, postoperative complications and enhanced recovery after surgery for patients with operable lung cancer. In consideration of some limitations of enrolled studies, the conclusion should be carefully applied. Further high-quality randomized controlled trials are needed.

\section{Abbreviations}

95\% Cl: 95\% confidence intervals; MD: Mean difference; MST: Muscle-sparing thoracotomy; NSCLC: Non-small cell lung cancer; OR: Odds ratios; VATS: Video-assisted thoracoscopic surgery

\section{Acknowledgments}

Not applicable.

\section{Authors' contributions}

$\mathrm{LL}$ is the corresponding author. $\mathrm{LL}, \mathrm{WZ}$ and $\mathrm{ZJ}$ designed the study. PL, TJ and WZ collected the data. WZ and CJ analyzed the data. PL and WZ wrote the manuscript. LL, WZ and CN reviewed the manuscript. All authors read and approved the final manuscript.

\section{Funding}

This work was supported by the 1.3.5 Project for Disciplines of Excellence (ZYJC18009), West China Hospital, Sichuan University for data collection and data processing. No financial support was received in the design of the study and collection, analysis, and interpretation of data and writing the manuscript.

\section{Availability of data and materials}

All data generated or analyzed during this study are included in this published article.

\section{Ethics approval and consent to participate}

Not applicable.

\section{Consent for publication}

Not applicable.

\section{Competing interests}

The authors declare that they have no competing interests.

Received: 20 May 2019 Accepted: 30 September 2019

Published online: 15 October 2019

\section{References}

1. Latshang T, Lo Cascio C, Russi E. Is lung cancer screening reasonable? Therapeutische Umschau Revue therapeutique. 2012;69(7):389-93.

2. Torre LA, Bray F, Siegel RL, Ferlay J, Lortet-Tieulent J, Jemal A. Global cancer statistics, 2012. CA Cancer J Clin. 2015:65(2):87-108.

3. Evans M. Lunge cancer: needs assessment, treatment and therapies. $\mathrm{Br}$ J Nurs. 2013;22(17):S15-6 s8, s20-2.

4. Ettinger DS, Wood DE, Aisner DL, Akerley W, Bauman J, Chirieac LR, et al. Non-small cell lung Cancer, version 5.2017, NCCN clinical practice guidelines in oncology. J Natl Compr Canc Netw. 2017;15(4):504-35.

5. Torre LA, Siegel RL, Jemal A. Lung Cancer statistics. Adv Exp Med Biol. 2016; 893:1-19.

6. Cheng AM, Wood DE. VATS versus open surgery for lung cancer resection: moving beyond the incision. J Natl Compr Canc Netw. 2015; 13(2):166-70.

7. Hanson JA, Armstrong P. Staging intrathoracic non-small-cell lung cancer. Eur Radiol. 1997;7(2):161-72.
8. Hazelrigg SR, Landreneau RJ, Boley TM, Priesmeyer M, Schmaltz RA, Nawarawong $W$, et al. The effect of muscle-sparing versus standard posterolateral thoracotomy on pulmonary function, muscle strength, and postoperative pain. J Thorac Cardiovasc Surg. 1991;101(3):394-400 discussion -1 .

9. Li S, Feng Z, Wu L, Huang Q, Pan S, Tang X, et al. Analysis of 11 trials comparing muscle-sparing with posterolateral thoracotomy. Thorac Cardiovasc Surg. 2014;62(4):344-52.

10. Ziyade S, Baskent A, Tanju S, Toker A, Dilege S. Isokinetic muscle strength after thoracotomy: standard vs. muscle-sparing posterolateral thoracotomy. Thorac Cardiovasc Surg. 2010;58(5):295-8.

11. Vannucci F, Gonzalez-Rivas D. Is VATS lobectomy standard of care for operable non-small cell lung cancer? Lung Cancer. 2016;100:114-9.

12. Zhu M, Fu XN, Chen X. Lobectomy by video-assisted thoracoscopic surgery (VATS) for early stage of non-small cell lung cancer. Front Med. 2011:5(1):53-60.

13. Okabe H, Tsunoda S, Tanaka E, Hisamori S, Mizumoto M, Murakami K, et al. Advantages and pitfalls of minimally invasive surgery for esophagogastric junction tumors. Nihon Geka Gakkai zasshi. 2015;116(1):45-9.

14. Jadad AR, Moore RA, Carroll D, Jenkinson C, Reynolds DJ, Gavaghan DJ, et al. Assessing the quality of reports of randomized clinical trials: is blinding necessary? Control Clin Trials. 1996:17(1):1-12.

15. Santambrogio L, Nosotti M, Bellaviti N, Mezzetti M. Videothoracoscopy versus thoracotomy for the diagnosis of the indeterminate solitary pulmonary nodule. Ann Thorac Surg. 1995;59(4):868-70 discussion 70-1.

16. Nomori $H$, Horio $H$, Naruke $T$, Suemasu K. What is the advantage of a thoracoscopic lobectomy over a limited thoracotomy procedure for lung cancer surgery? Ann Thorac Surg. 2001;72(3):879-84.

17. Ilonen IK, Rasanen JV, Knuuttila A, Salo JA, Sihvo El. Anatomic thoracoscopic lung resection for non-small cell lung cancer in stage I is associated with less morbidity and shorter hospitalization than thoracotomy. Acta Oncol. 2011;50(7):1126-32.

18. Kirby TJ, Mack MJ, Landreneau RJ, Rice TW. Lobectomy--video-assisted thoracic surgery versus muscle-sparing thoracotomy. A randomized trial. J Thorac Cardiovasc Surg. 1995:109(5):997-1001 discussion -2.

19. Kuritzky AM, Aswad BI, Jones RN, Ng T. Lobectomy by video-assisted thoracic surgery vs muscle-sparing thoracotomy for stage I lung Cancer: a critical evaluation of short- and long-term outcomes. J Am Coll Surg. 2015; 220(6):1044-53.

20. Giudicelli R, Thomas P, Lonjon T, Ragni J, Morati N, Ottomani R, et al. Videoassisted minithoracotomy versus muscle-sparing thoracotomy for performing lobectomy. Ann Thorac Surg. 1994;58(3):712-7 discussion 7-8.

21. Wang BY, Liu CC, Shih CS. Short-term results of thoracoscopic lobectomy and segmentectomy for lung cancer in koo foundation sun yat-sen cancer center. J Thorac Dis. 2010;2(2):64-70.

22. Zhao Y, Li G, Zhang Y, Hu H, Zhang J, Sun Y, et al. Comparison of outcomes between muscle-sparing thoracotomy and video-assisted thoracic surgery in patients with CT1 N0 M0 lung cancer. J Thorac Cardiovasc Surg. 2017. 2017;154(4):1420-1429.e1. https://doi.org/10.1016/j.jtcvs.2017.04.071

23. Usuda K, Maeda S, Motomo N, Tanaka M, Ueno M, Machida Y, et al. Pulmonary function after lobectomy: video-assisted thoracoscopic surgery versus muscle-sparing mini-thoracotomy, Indian J Surg. 2017:79(6):504-9.

24. Erus S, Tanju S, Kapdagli M, Ozkan B, Dilege S, Toker A. The comparison of complication, pain, quality of life and performance after lung resections with thoracoscopy and axillary thoracotomy. Eur J Cardiothorac Surg. 2014; 46(4):614-9.

25. Menna C, De Falco E, Teodonio L, Andreetti C, Maurizi G, Ciccone AM, et al. Surgical wound-site inflammation: video-assisted thoracic surgery versus thoracotomy. Interact Cardiovasc Thorac Surg. 2019;28(2):240-6.

26. Chen K, Wang X, Yang F, Li J, Jiang G, Liu J, et al. Propensity-matched comparison of video-assisted thoracoscopic with thoracotomy lobectomy for locally advanced non-small cell lung cancer. J Thorac Cardiovasc Surg. 2017:153(4):967-76 e2.

27. Liu L. Video-assisted resection for lung cancer results in fewer complications. J Thorac Cardiovasc Surg. 2015:150(3):739-40.

28. Port JL, Mirza FM, Lee PC, Paul S, Stiles BM, Altorki NK. Lobectomy in octogenarians with non-small cell lung cancer: ramifications of increasing life expectancy and the benefits of minimally invasive surgery. Ann Thorac Surg. 2011:92(6):1951-7.

29. Klapper J, D'Amico TA. VATS versus open surgery for lung cancer resection: moving toward a minimally invasive approach. J Natl Compr Canc Netw. 2015:13(2):162-4. 
30. Petersen RP, Pham D, Burfeind WR, Hanish SI, Toloza EM, Harpole DH Jr, et al. Thoracoscopic lobectomy facilitates the delivery of chemotherapy after resection for lung cancer. Ann Thorac Surg. 2007;83(4):1245-9 discussion 50

31. Zhi X, Gao W, Han B, Yang Y, Li H, Liu D, et al. VATS lobectomy facilitates the delivery of adjuvant docetaxel-carboplatin chemotherapy in patients with non-small cell lung cancer. J Thorac Dis. 2013;5(5):578-84.

32. Berry MF, Hanna J, Tong BC, Burfeind WR Jr, Harpole DH, D'Amico TA, et al. Risk factors for morbidity after lobectomy for lung cancer in elderly patients. Ann Thorac Surg. 2009;88(4):1093-9.

33. Cattaneo SM, Park BJ, Wilton AS, Seshan VE, Bains MS, Downey RJ, et al. Use of video-assisted thoracic surgery for lobectomy in the elderly results in fewer complications. Ann Thorac Surg. 2008;85(1):231-5 discussion 5-6.

34. Menna C, De Falco E, Teodonio L, Andreetti C, Maurizi G, Ciccone AM, et al. Surgical wound-site inflammation: video-assisted thoracic surgery versus thoracotomy. Interact Cardiovasc Thorac Surg. 2018. 34: 2019 1;28(2):240246. https://doi.org/10.1093/icvts/ivy231.

35. Park BJ, Flores RM. Cost comparison of robotic, video-assisted thoracic surgery and thoracotomy approaches to pulmonary lobectomy. Thorac Surg Clin. 2008;18(3):297-300 vii.

36. Burfeind WR Jr, Jaik NP, Villamizar N, Toloza EM, Harpole DH Jr, D'Amico TA. A cost-minimisation analysis of lobectomy: thoracoscopic versus posterolateral thoracotomy. Eur J Cardiothorac Surg. 2010;37(4):827-32.

37. Yan TD, Cao C, D'Amico TA, Demmy TL, He J, Hansen H, et al. Video-assisted thoracoscopic surgery lobectomy at 20 years: a consensus statement. Eur J Cardiothorac Surg. 2014;45(4):633-9.

\section{Publisher's Note}

Springer Nature remains neutral with regard to jurisdictional claims in published maps and institutional affiliations.

Ready to submit your research? Choose BMC and benefit from:

- fast, convenient online submission

- thorough peer review by experienced researchers in your field

- rapid publication on acceptance

- support for research data, including large and complex data types

- gold Open Access which fosters wider collaboration and increased citations

- maximum visibility for your research: over $100 \mathrm{M}$ website views per year

At BMC, research is always in progress.

Learn more biomedcentral.com/submissions 